RASĀYAN J. Chem.

Vol. 13 | No. 1 |18 - 23| January - March | 2020 ISSN: 0974-1496 | e-ISSN: 0976-0083 | CODEN: RJCABP

\title{
IDENTIFICATION OF SECONDARY METABOLITE OF LABAN LEAF EXTRACT (VITEX PINNATA L) FROM GEOTHERMAL AREAS AND NON-GEOTHERMAL OF AGAM MOUNTAINS IN ACEH BESAR, ACEH PROVINCE, INDONESIA
}

\author{
Cut Nuraskin*, ${ }^{1,2}$, Marlina $^{3}$, R. Idroes ${ }^{4}$, C. Soraya ${ }^{5}$ and Djufri ${ }^{6}$ \\ ${ }^{1}$ Graduate School of Mathematics and Applied Sciences, Universitas Syiah Kuala, Kopelma \\ Darussalam, Banda Aceh, 23111, Indonesia \\ ${ }^{2}$ Department of Dental Nursing, Polytechnic of Health-Ministry of Health, Aceh, 23231, \\ Indonesia \\ ${ }^{3}$ Chemistry Department, Faculty of Mathematics and Natural Sciences, Universitas Syiah Kuala, \\ Banda Aceh, 23111, Indonesia \\ ${ }^{4}$ Pharmacy Department, Faculty of Mathematics and Natural Sciences, Universitas Syiah Kuala, \\ Banda Aceh, 23111, Indonesia \\ ${ }^{5}$ Conservative Dentistry Department, Faculty of Dentistry, Universitas Syiah Kuala, Banda \\ Aceh, 23111, Indonesia \\ ${ }^{6}$ Biology Education Department, Faculty of Teacher Training and Education, Universitas Syiah \\ Kuala, Banda Aceh, 23111, Indonesia \\ *E-mail: cutajanuraskin2@gmail.com
}

\begin{abstract}
The purpose of this study was to analyze the comparison of the number of Laban leaf extracts from geothermal and non-geothermal regions, calculating yield values, and identifying active compounds in Laban leaves taken from geothermal and non-geothermal regions in Aceh Besar, Aceh Province. The study was started by extracting Laban leaves by maceration method, using n-hexane, ethyl acetate and methanol for $3 \times 24$ hours. Then the extract was concentrated with a Rotary evaporator, calculated yield value, and phytochemical test. The results of the identification showed that there were differences in extract weight and weight of yields in the leaves in geothermal and non-geothermal regions. In n-hexane extract, the weight difference of extract was $37.6 \mathrm{~g}$, and the difference in weight of the yield was $1.25 \%$. In ethyl acetate extract the extract weight difference was $98.57 \mathrm{~g}$, and the weight difference in yield was 3.28\%. Methanol extract weight difference is $427.33 \mathrm{~g}$, and the difference in weight of the yield was $11.59 \%$. The biggest difference is found in methanol extract.
\end{abstract}

Keywords: Identification, Secondary Metabolites, Laban leaves, Geothermal Areas, and Non-geothermal

(c) RASĀYAN. All rights reserved

\section{INTRODUCTION}

Laban plants (Vitex pinnata L) are one of the herbal medicines that often used by a community to cure diarrhea and dysentery. Laban plants (Vitex pinnata L) are widely found in the province of Aceh. They are found in geothermal areas in the Ie Seu Um Aceh Besar area. The Ie Seu Um area is a geothermal manifestation area located in the geothermal outflow zone of Agam volcano. The geothermal area is at an altitude of 59 to $89 \mathrm{~m}$ above sea level. Geographical location and environmental conditions have an impact on the biosynthesis of plant secondary metabolites and can increase the number of secondary metabolites such as phenols, and alkaloids. ${ }^{1}$ Laban plants grow in the tropics with a tree height of 25-30

Rasayan J. Chem., 13(1), 18-23(2020)

http://dx.doi.org/10.31788/RJC.2020.1315434

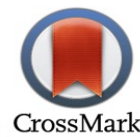


RASĀYAN J. Chem.

Vol. 13 | No. 1 |18-23| January - March | 2020

$\mathrm{m}$, with hardwood and branching structures. ${ }^{2}$ Laban also contains other components such as lignans, phenylpropanoids, sesquiterpenoids, and iridoid glycosides. ${ }^{3}$ Laban leaf is widely used as herbal medicine by indigenous peoples. ${ }^{4}$ Efficacy of Laban Leaf has also been widely carried out such as anti-microbial ${ }^{5}$, anti-fungal ${ }^{6}$. Laban leaves can also be used to reduce heat (antipyretics), flu, cough ${ }^{5}$, diarrhea, and antitoxic antidotes ${ }^{7}$, and have anti-breast cancer agents in humans. ${ }^{8,9}$ The stem of the Laban plant (Vitex pinnata L.) contains compounds that are pinnatifida antifungal against Candida albicans. ${ }^{10}$ The community of $\mathrm{Ie} \mathrm{Seu} \mathrm{Um} \mathrm{region} \mathrm{uses} \mathrm{laban} \mathrm{plants} \mathrm{to} \mathrm{treat} \mathrm{diarrhea} \mathrm{and} \mathrm{dysentery} \mathrm{and} \mathrm{heal} \mathrm{wounds.}{ }^{11}$ The aim of this study was to examine the calculation of the extract curse quality, organoleptic, extract weight, yield weight, simplicity weight, weight of fresh leaf samples obtained from the extraction process. Furthermore, phytochemical testing was carried out to determine the secondary metabolite class.

\section{EXPERIMENTAL}

\section{Material}

The material studied was Laban leaves (Vitex pinnata), using three solvents, n-hexane, ethyl acetate, and methanol. Distilled water was used to dissolve the extract. DMSO (Dimethyl Sulfoxide) Polarity Solvent was used to help dissolve extracts in aqua dest and dissolve special reagents in phytochemical extract testing.

\section{Tool}

The equipment used was maceration tools, rotary evaporators, porcelain plates, test tubes, test tube racks, analytical scales, vial bottles, and other supporting tools.

\section{Sampling}

Wet leaf samples were taken from geothermal and non-geothermal of Aceh Besar for $10 \mathrm{~kg}$ each. Then they were cleaned, dried and mashed using a blender until in the form of powder. ${ }^{11}$ The simplicia obtained was then weighed for rendement calculation data. ${ }^{12}$

\section{Extraction}

Samples fine powder was weighed $3 \mathrm{~kg}$ of leaf powder, macerated successively with $\mathrm{n}$-hexane, ethyl acetate and methanol for $3 \times 24$ hours until the solvent was clear. The filtrate was evaporated with a rotary evaporator to obtain concentrated $n$-hexane extract, ethyl acetate extract, and methanol extract ${ }^{13}$. Phytochemical tested n-hexane, ethyl acetate, methanol extract Before being used first, extract quality was tested, organoleptic test, shrinkage weight, extract weight, rendement weight, simplicia weight, fresh sample weight, preference test.

\section{Phytochemical Test}

Phytochemical screening was a qualitative examination of secondary metabolites of biologically active compounds found in plants. ${ }^{14}$

\section{Identification of Triterpenoid Compounds and Steroids}

Extract solution plus anhydrous acetic acid until the substance was submerged. Then leave it for 15 minutes and added 1 drop of concentrated sulfuric acid. The next step was observing color changes. When blue-green was formed then the results were positive for steroids. When a purple color was formed, the result was positive for the triterpenoid.

\section{Identification of Alkaloid Compounds}

As much as $2 \mathrm{ml}$ of extract was added $1.5 \mathrm{ml}$ of $2 \%$ hydrochloric acid. The solution is divided into 3 test tubes. In tube 1 as a comparison, Meyer reagent 2 was added, and Dragendorff reagent was added to tube 3. The presence of alkaloids is indicated by turbidity or yellowish-white deposits on the addition of Meyer reagents, and red deposits on the addition of Dragendorff reagents.

\section{Identification of Flavonoids Compounds}

To identify flavonoids, a solution of magnesium metal was added and 4-5 drops of concentrated hydrochloric acid. The presence of flavonoid aglycones is indicated by a change in color to red or orange. 
RASĀYAN J. Chem.

Vol. 13 | No. 1 |18-23| January - March | 2020

Identification of Phenolic Compounds

To identify Phenolic Compounds, $2 \mathrm{ml}$ of extract were added with 3 drops of $\mathrm{Fe} \mathrm{Cl} 3$. If a green or blue solution is formed to black it shows the presence of phenolic compounds.

\section{Identification of Saponin Compounds}

To identify Saponin Compounds Extract solution was heated for 5 minutes, after cold filtered. The filtrate was shaken vertically for 1-2 minutes. Saponin compounds were indicated by the presence of foam which is $1 \mathrm{~cm}$ high and left for 1 hour. The foam was also formed on adding 1 drop of hydrochloric acid $(\mathrm{HCl})=$ $0.1 \mathrm{~N}$.

\section{Identification of Tanin Compounds}

The extract solution was added $1 \%$ gelatin to the test tube. Positive results were indicated by the formation of white deposits.

\section{Calculation of Extract Rendemen}

\section{RESULTS AND DISCUSSION}

Calculation of extract rendemen value the calculation of quality parameters extracted from the extract of Laban geothermal leaves obtained the lowest yield data obtained from the extract of $n$-hexane $(1.994 \%)$. The highest yield value is the extract of methanol (14.73\%). The lowest extract weight was n-hexane extract $(59.82 \mathrm{~g})$ and the highest extract weight was methanol extract $(442.06 \mathrm{~g})$. The following Table-1 is the result of the extraction of the geothermal leaf.

Table-1: Results of Extraction of Geothermal Laban Leaves

\begin{tabular}{c|c|c|c}
\hline No & Sample & Extract Weight $(\mathrm{G})$ & Rendemen Weight ( \% ) \\
\hline 1 & Concentrated Extract $n$-heksana & $59,82 \mathrm{~g}$ & $1,994 \%$ \\
\hline 2 & Concentrated Extract ethyl acetate & $189,089 \mathrm{~g}$ & $6,302 \%$ \\
\hline 3 & Concentrated Methanol Extract & $442,06 \mathrm{~g}$ & $14,73 \%$ \\
\hline
\end{tabular}

Remarks: counted to $3000 \mathrm{~g}$ of dried simplicia of laban leaves (\% Extract extract $=$ extract weight / sample weight) $\mathrm{x}$ 100)

Extracts obtained the lowest yield data is $\mathrm{n}$-hexane $(0.740 \%)$. The highest yield weight is methanol $(3.115 \%)$. The lowest extract weight was n-hexane extract $(22.22 \mathrm{~g})$ and the highest extract weight was methanol extract $(93.46 \mathrm{~g})$. The compounds contained in methanol extract are dominated by polar compounds such as flavonoids, glycosides, tannins, and several alkaloids. The following Table -2 is the result of the extraction of non-geothermal Laban leaves.

Table- 2: Results of Extraction of Non-Geothermal Leaves

\begin{tabular}{c|c|c|c}
\hline No & Sample & Extract Weight $(\mathrm{g})$ & Rendement Weight ( \% ) \\
\hline 1 & Concentrated n-hexane extract & $22,22 \mathrm{~g}$ & $0,740 \%$ \\
\hline 2 & Ethyl acetate concentrated extract & $90,57 \mathrm{~g}$ & $3,019 \%$ \\
\hline 3 & Methanol concentrated extract & $93,46 \mathrm{~g}$ & $3,115 \%$ \\
\hline Remarks: Counted to 3000 g of dried Simplicia of Laban Leaves $(\%$ Extract Extract $=$ Extract Weight / Samp
\end{tabular}

Remarks: Counted to $3000 \mathrm{~g}$ of dried Simplicia of Laban Leaves (\% Extract Extract = Extract Weight / Sample Weight) $\mathrm{x}$ 100)

The results of the different yields show different mass and secondary metabolite compounds. The higher the rendition value produced, the lower the quality obtained. Extreme environmental conditions affect the yield because plants can grow and adapt to the surrounding environment. In terms of biodiversity, plants found in geothermal regions have adaptive capacity to extreme environmental conditions.

\section{Comparison of Number of Extracts}

Based on the results of the comparison of the number of extracts, it is known that the geothermal yield weight is greater than non-geothermal. The biggest difference between extract weight and yield weight in geothermal and non-geothermal leaves is found in methanol extract. The difference in the weight of the 
RASĀYAN J. Chem.

Vol. 13 | No. 1 |18 - 23| January - March | 2020

extract of methanol is $427.33 \mathrm{~g}$, and the weight of the crude extract is $11.59 \%$. The polar compound component in methanol extract is more than the compound component in n-hexane extract and ethyl acetate extract ${ }^{15}$. Table -3 below is the result of extracting geothermal and non-geothermal rice leaves.

Table-3: Results of Extraction of Geothermal and Non-Geothermal Leaves Geothermal Non-Geothermal Samples

\begin{tabular}{l|c|c|c|c}
\hline \multirow{2}{*}{ Sample } & \multicolumn{2}{|c|}{ Geothermal } & \multicolumn{2}{c}{ Non-Geotermal } \\
\cline { 2 - 4 } & $\begin{array}{c}\text { Extract } \\
\text { Weight }(\mathrm{G})\end{array}$ & $\begin{array}{c}\text { Rendemen Weight } \\
(\%)\end{array}$ & $\begin{array}{c}\text { Extract } \\
\text { Weight }(\mathrm{G})\end{array}$ & $\begin{array}{c}\text { Rendemen } \\
\text { Weight }(\%)\end{array}$ \\
\hline Concentrated n-hexane extrac & $59.82 \mathrm{~g}$ & $1.99 \%$ & $22.22 \mathrm{~g}$ & $0.74 \%$ \\
\hline Ethyl acetate concentrated extract & $189.08 \mathrm{~g}$ & $6.3 \%$ & $90.57 \mathrm{~g}$ & $3.02 \%$ \\
\hline Methanol concentrated extract & $442.06 \mathrm{~g}$ & $14.73 \%$ & $93.46 \mathrm{~g}$ & $3.12 \%$ \\
\hline
\end{tabular}

Remarks: Counted to $3000 \mathrm{~g}$ of Dried Simplicia of Laban Leaves (\% Extract Extract $=$ Extract Weight $/$ Sample Weight) x 100).

The results of the comparison of the amount of leaf extract in the geothermal and non-geothermal regions. The difference in weight of hexane extract was $37.6 \mathrm{~g}$, and the difference in weight of the yield was $1.25 \%$. In ethyl acetate extract the extract weight difference was $98.57 \mathrm{~g}$, and the weight difference in yield was $3.28 \%$. Methanol extract weight difference is $427.33 \mathrm{~g}$, and the weight difference in yield was $11.59 \%$. Figure graph (1) the following is a comparison of extract weight and weight of yield between leaves of geothermal and non-geothermal.

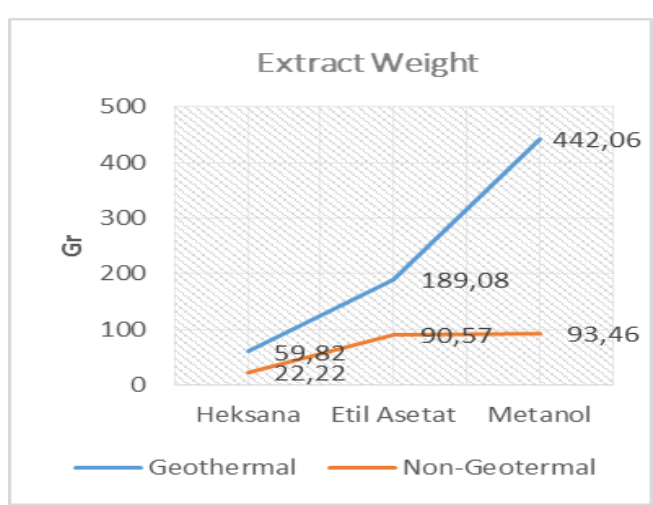

(a)

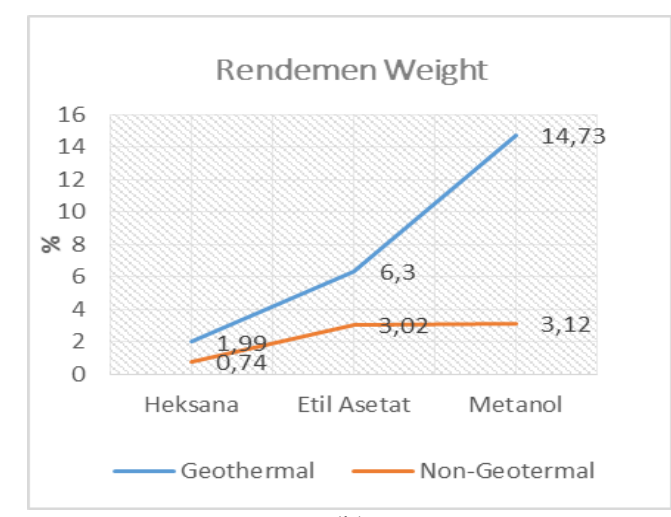

(b)

Fig.-1: (a) Comparison of Extracts Geothermal and Non-Geothermal,(b) Comparison of Rendemen Geothermal and Non-Geothermal

\section{Organoleptic Test}

Organoleptic test or sensory test is a test using the human senses as a means of measuring the power of acceptance of materials or samples. Organoleptic tests were carried out on the leaves of rice in the geothermal region, and leaf Laban in the non-geothermal region. An oligopolistic test was carried out on $\mathrm{n}$-hexane, ethyl acetate, and methanol extract based on specific parameters. Table -4 below is the results of organoleptic tests on leaves of geothermal and non-geothermal fields.

\section{Fitoemia Test}

Phytochemical tests are to determine secondary metabolites contained in plants. Phytochemical tests were carried out on n-hexane, ethyl acetate and methanol extract in geothermal and non-geothermal leaves. Phytochemical tests include tests of alkaloids, steroids, terpenoids, saponins, flavonoids, phenolics and tannins. Test results of secondary metabolites on leaf extracts of Laban in the geothermal region showed that n-hexane extracts were positive containing steroids, phenolics, and tannins. Ethyl acetate extract positively contains alkaloids with dragendroff, Wagner, steroid, terpenoids, flavonoids, and phenolic reagents. The methanol extract positively contains alkaloids with Mayer, dragendroff, steroids, terpenoids, saponins, flavonoids, phenolic, and tannin. Table -5 below is the test result. 
RASĀYAN J. Chem.

Vol. 13 | No. 1 |18 - 23| January - March | 2020

Table- 4: Organoleptic Test Results

\begin{tabular}{c|c|c|c|c|c|c}
\hline \multicolumn{4}{|c}{ Laban Geothermal Leaves } & \multicolumn{2}{c}{ Laban Non-geothermal Leaves } \\
\hline Organoleptic & $n$-hexane & Ethyl ecetate & Methanol & N-Heksane & $\begin{array}{c}\text { Ethyl } \\
\text { Asetate }\end{array}$ & Methanol \\
\hline Colour & Black to dark black & Dark pitch & Black & Black & Black & Black \\
\hline Smile & Odor of Leaves & Hena & Hena & Leaves & Leaves & Leaves \\
\hline Consistency & Thick & Thick & Thick & Thick & Thick & Thick \\
\hline
\end{tabular}

Tabel -5: The Content of Secondary Metabolites of Leaves of Laban Geothermal Extract.

\begin{tabular}{c|c|c|c}
\hline Metabolites sekunder & n-heksana Extract & Ethyl Acetate Exstract & Metanol Exstract \\
\hline Alkaloid & & & - \\
\hline Mayer & - & + & + \\
\hline dragendrof & - & + & + \\
\hline wagner & - & + & + \\
\hline Steroid & + & + & + \\
\hline Terpenoid & - & + & + \\
\hline Saponin & - & + & + \\
\hline Flavonoids & + & - & + \\
\hline phenolic & + & & + \\
\hline Tanin & & & + \\
\hline
\end{tabular}

Description: (+) Positive for the Presence of Secondary Metabolites, (-) Negative There is no Secondary Metabolite Content

Test results in secondary metabolites on Laban leaf extract non-geothermal extracts of n-hexane are known to be positive containing steroids, phenolic. Ethyl acetate extract positively contains alkaloids with dragendroff, Wagner, steroid, saponin, phenolic reagents. Methanol extract positively contains alkaloids with major reagents, dragendroff, steroids, terpenoid, saponin, phenolic. Table -6 below is the test result of the content of secondary metabolites of non-geothermal leaf extract.

Table- 6: The Content of Secondary Metabolites of Non-Geothermal Rice Leaves

\begin{tabular}{c|c|c|c}
\hline Secondary Metabolite Extract & n-hekxana Extract & Ethyl Acetate Extract & Methanol Extract \\
\hline Alkaloid & & & + \\
\hline Mayer & - & - & + \\
\hline Dragendrof & - & + & + \\
\hline Wagner & - & + & + \\
\hline Steroids & + & - & + \\
\hline Terpenoid & - & + & - \\
\hline Saponin & - & - & + \\
\hline Flavonoids & - & + & - \\
\hline Phenolic & + & - & + \\
\hline Tanin & - & + & + \\
\hline
\end{tabular}

Description: (+) positive for the presence of secondary metabolites, (-) Negative there is no secondary metabolite content.

The secondary metabolite content of non-geothermal leaf n-hexane extract did not contain secondary metabolites of alkaloids and saponins. The secondary metabolite of ethyl acetate extract does not contain terpenoids and flavonoids. Secondary metabolites in the methanol extract of non-geothermal leaves are not flavonoids. Flavonoid compounds in plants are a natural source of antioxidants that can inhibit the development of several types of diseases in humans, such as cardiovascular diseases and cancer ${ }^{17}$. Laban leaves contain flavonoids, saponins, tannins, triterpenoids/steroids, and glycosides ${ }^{6}$. Laban also contains other components such as lignans, phenylpropanoids, sesquiterpenoids, and iridoid glycosides ${ }^{4}$. The antimicrobial mechanism of phenolic compounds damages lipids in the plasma membrane of microorganisms which causes the contents of cells to come out ${ }^{13}$. Some tannin derivatives and flavonoids have antimotility, antisecretory, anti-dysentery, anti-inflammatory, analgesic and antibacterial activities ${ }^{18,6}$. 
RASĀYAN J. Chem.

Vol. 13 | No. 1 |18 - 23| January - March | 2020

\section{CONCLUSION}

The results of the identification showed that there were differences in extract weight and weight of yields in the leaves of rice in geothermal and non-geothermal regions. Test results of secondary metabolites of laban leaf extract in the geothermal region showed that the n-hexane extract was positive containing steroids, phenolics, and tannins. The methanol extract of Laban leaves in the geothermal region positively contains alkaloids with Mayer, dragendroff, steroids, terpenoids, saponins, flavonoids, phenolic, and tannin. Test results in secondary metabolites on Laban leaf extract non-geothermal extracts of n-hexane are known to be positive containing steroids, phenolic. Ethyl acetate extract positively contains alkaloids with dragendroff, Wagner, steroid, saponin, phenolic reagents. Methanol extract positively contains alkaloids with major reagents, dragendroff, steroids, terpenoid, saponin, phenolic.

\section{ACKNOWLEDGMENT}

Thanks to Universitas Syiah Kuala to provide the facility to fulfill this study.

\section{REFERENCES}

1. K. L. Compean, and A.Y. Nalvez, Research Journal of Medicinal Plants, (8), 204(2014), DOI: 10.3923/rjmp.2014.204.213

2. Thenmozhi, and U. Subasini, European Journal of Biomedical and Pharmaceutical Sciences, 3(1), 191(2016).

3. S. Ganapaty, and K. N. Vidyadhar, Journal of Natural Remedies, 5(2), 7(2005), DOI: $10.18311 / \mathrm{jnr} / 2005 / 391$

4. A. Rani, and Sharma, Phcog Rev, 7, 188(2013)

5. R. Venkataswamy, Doss, and A. Sukumar, Journal of Pharmaceutical Sciences, 72(2), 229(2010), DOI: $10.4103 / 0250-474 X .65020$

6. H.A. Oramahi, and Yoshimura, Journal of Wood Science, 5(9), 344(2013), DOI: 10.1007/s10086013-1340-8

7. AK. Meena, Niranjan, M.M.Rao, Padhi, and R.A Babu, Asian Journal of Traditional Medicines, 6 (2), 54(2011)

8. Y. Deng, Chin, Y.W. Chai, H.B De Blanco, E.C Kardono, L.B.S. Riswan, and A.D.Kinghorn, Phytochemistry Letters, 4(3), 213(2011), DOI: 10.1016/j.phytol.2011.03.007

9. M.A.Khan, Shah, and A. Gilani, Bangladesh Journal of Pharmacology, 8(3), 317(2013), DOI: 10.3329/bjp.v8i3.15296

10. Ata A, Mbong N, C.D. Iverson, R.Samarasekera. Nat Prod Commun., 4(1),1(2009)

11. R. Idroes, Khairan, and F. Fajar, Syiah Kuala Universiti Press, 58 (2016).

12. SK Biswas, Cowdhury, Karmakar UK, and Shill MC R, Journal of Applied Pharmaceutical Science 1(6), 112(2011)

13. F Rinaldi, Albrahim, and LR Jaka F, Proceeding of Mulawarman Pharmaceuticals Conferences, 4(1), 133(2016), DOI: 10.25026/mpc.v4i1.172

14. A. Hermansah, Harlia, and T.A. Zahara, Jurnal Kimia Khatulistiwa, 4(2), 67(2015)

15. M.I. Noor, E.Y and Z, J. Aceh. Phys. Soc., 5(1), 14(2016)

16. R.Turalely, H. Ruslin, and F.Mahulete, biofarmaka IPB, (2013)

17. Sumaiyah, Masfria and A. Dalimunth, Rasayan J. Chem., 11(2), 505(2018), DOI:10.31788/RJC.2018.1122068.

18. L. A. Otshudi, A. Vercruysse, Journal Ethnopharmacol, 71(3), 411(2000), DOI:10.1016/S03788741(00)00167-7

[RJC-5434/2019] 